\title{
Interactive comment on "Science, Poetry, and Music for Landscapes of the Marche Region, Italy. Teaching the Conservation of Natural Heritage" by Olivia Nesci and Laura Valentini
}

\section{Sydney Lancaster (Referee)}

sydney.lancaster@gmail.com

Received and published: 9 June 2020

This paper describes a project which uses music and poetry to increase interest in, and understanding of, the geological and geomorphological landscapes in the Marche Region (Italy). The project described employs a range of media and experimental means to convey information and appreciation of the landscape of the region and its geological processes to good effect. The paper and the project described therein are well suited for publication in Geoscience Communication.

There is mention made in this paper of the size and demographics of audiences attending public presentations of this work; the authors are encouraged to provide this

Printer-friendly version

Discussion paper 
data as a supplementary table if it is at all available. I look forward to reading about further developments in the next phase of this project, as the research will include more data from audience feedback and demographics; this information can be very useful in gauging the success of the project overall, and in determining the most effective elements of a complex project. I encourage the authors to gather and share data regarding online reception/viewing/comments for the project as well, as this can contribute to an understanding of the international reach of the work.

I would encourage greater detail in labelling figures and in the figure captions; for those of us unfamiliar with the locations, more information in both the figures and their captions would contribute to our understanding.

The manuscript is generally well organized and written, and requires only minor revisions - mostly to phrasing, and small technical corrections, which are suggested below. Please refer to the accompanying marked-up manuscript uploaded as a supplement to this review for recommendations regarding word choice and phrasing for clarity.

Technical Corrections line 38, add an 's' to reference line 80, add comma after equilibrium line 189, add comma after relief line 283, add comma after territory line 285, insert 'of' after type line 287, add comma after anticline line 288, add comma after ) line 397, insert 'and' before balance line 429, delete 'at the' and change mirror to mirrored line 437, replace period after strong with a colon; change It to it following colon line 438, insert 'the principle melody,' before concrete line 439, insert comma after movement line 448, insert comma after form

Please also note the supplement to this comment: https://gc.copernicus.org/preprints/gc-2020-5/gc-2020-5-RC3-supplement.pdf

Interactive comment on Geosci. Commun. Discuss., https://doi.org/10.5194/gc-2020-5, 2020. 